\title{
Waiting for the Referee or Refereeing the Wait? CCO's Role in Hosting and Deploying the Wait Time Information System in Ontario
}

Terrence Sullivan

$\mathrm{n}$ the late $1990 \mathrm{~s}$, Ontario joined a number of other provinces in referring cancer patients out of the country for radiation treatment. The province and its cancer agency had failed to build sufficient capacity in anticipation of a highly predictable increase in the demand for radiation in Ontario. Public discontent with cancer services and Ontario's cancer agency in 2001 led to some dramatic strategic and operational changes in 2002/03, resulting in a revised business model for Cancer Care Ontario (CCO) (Sullivan et al. 2004). In the fall of 2003, the newly minted Cancer Quality Council of Ontario released a book based on what was known and available through information systems to drive the improvement in quality of cancer services. This volume sketched out a preliminary agenda for quality that is still being pursued today (Sullivan et al. 2003). In spring 2004, the Quality Council introduced a four-point strategy for wait time reductions, which included a focus on reducing demand for cancer services, increasing the supply of cancer resources, coordinating access to cancer services and increasing the efficiency of existing resources.

When the province selected former CCO chief Alan Hudson to lead the effort to reduce wait times, it was logical that, with its expertise and experience, CCO would be a strong and committed partner in addressing the backlog for a range of cancer services, including radiation and surgery.

As an extension of its own imperative to reduce wait times for cancer patients, CCO became the technical and logistical home for the overall Wait Time Strategy. In addition, CCO had the systems capacity, the organizational commitment and a province-wide mandate that had already been demonstrated in other areas, including electronic pathology reporting.

$\mathrm{CCO}$ had also just hired a talented new Chief Information Officer (CIO) in the person of Sarah Kramer, who had the necessary ambition and competence to provide part-time support for the Wait Times program. The larger effort, under Alan Hudson's leadership, included Sarah and a team of specialty practice leaders in each of the "big five" wait time reduction candidates specified by the first ministers in 2004.

Additionally, as a consequence of the newly introduced Personal Health Information Protection Act (PHIPA) in Ontario, $\mathrm{CCO}$ was moving from what was already a secure environment for health information to an extremely high security environment for personal health data collection, use and disclosure.

In many respects, the introduction of the Wait Time Information System (WTIS) was the beginning of a journey without a clear destination for $\mathrm{CCO}$ and for the Ontario government. What were the boundaries of the wait times program? Who would use the data beyond public reporting and how long would this effort on wait times management endure? Would incremental wait times funding to hospitals be sustained or rebased?

Nevertheless, CCO and the wait times leadership determined that it would be best to enter this journey with a very strong organizational commitment, both in consideration 
of our own strategic objective of improving access for cancer services and in the broader healthcare debate on access that was made all the more acute with the Chaoulli decision from the Supreme Court in June of 2005 (Flood and Sullivan 2005). The decision to support the Ontario wait times initiative with technical resources from CCO was neither simple nor taken lightly. The collection of wait time information in Ontario had been, ironically, a point of pride for CCO, which had been disclosing radiation wait times for many years. That systemic therapy wait times were not falling and that surgical wait times were growing (Simunovic et al. 2005) presented the opportunity for strategic alignment between CCO's objectives and the much broader "big five" objectives of wait time reductions for cardiac procedures, cataract surgery, cardiovascular surgery, hip and knee replacement surgery and CT and MRI scans. In short, CCO had the organizational conviction and alignment, a provincial platform, a well-developed methodology for engaging practice leaders in medicine and a new business model that fit well with the collection and use of wait time information to drive improvements in cancer services (Dobrow et al. 2008). CCO was and remains a very active silent partner, providing organizational and information infrastructure to the WTIS.

The decision for CCO to host, build and deploy a wait time information system for Ontario was somewhere between a planning decision and a decision to implement and rapidly adapt to a set of changing circumstances in the Ontario healthcare landscape, where the provincial government had committed to a significant transformation agenda. With Sarah Kramer's CIO leadership and Alan Hudson's provincial wait times leadership, we planned and adapted in bite-sized steps the introduction of the WTIS, first with the major hospitals in relation to the big five, and then in a broader implementation to capture all surgical waits across Ontario.

In the early stages, this was a difficult and challenging deployment for CCO because of the imperatives of time and the challenges and constraints of a public agency commissioning large pieces of work in short turning circles with expensive price tags. In all of this, a continuous exchange went on between the wait times leadership and CCO around the need to develop a predictable privacy-sensitive platform going forward, and the continuous make-or-buy challenges in hiring, housing and attracting an ever-movable brigade of staff talent and consulting expertise to deliver on the wait times design, deployment and operations. At the end of the day, what we have developed together is a platform for wait times information filtering, collecting and disclosure that will have a range of future information management applications and a range of important but, as yet, unexploited research applications (Sullivan 2006). We also developed, with our own cancer panels, workable priority definitions for triaging waits into acuity categories.

Going forward, with the introduction of our new e-Health agency in Ontario, there will, of course, be questions about the eventual alignment of the WTIS and the broader "access to care" agenda; however, our current challenges remain. They are the challenges expanding the access to care agenda, as well as the newly emerging challenge of collecting and disclosing colonoscopy volumes and wait times in support of a colorectal screening program in Ontario. CCO commissions colonoscopy volumes and links the collection of data quality standards and reporting in a fashion pioneered through the WTIS for cancer surgery.

When challenged with the prospect of deploying an information system for wait times in Ontario, CCO was faced with either waiting for the provincial referee to provide an overall road map, or playing a leadership role in building, developing and refining a system. At the end of the day, we opted for the latter and we have never looked back.

The creation and consolidation of the new Ontario e-Health agency now presents exciting prospects for a future where we may be able to monitor, report and improve wait time performance in a range of areas where the citizens of Ontario rightly deserve timely access to quality care. This future will build on the strong information management tools that the WTIS has allowed us to develop together with hospital and clinical leaders across Ontario.

\section{References}

Dobrow, M.J., T. Sullivan and C. Sawka. 2008. "Shifting Clinical Accountability and the Pursuit of Quality: Aligning Clinical and Administrative Approaches." Healthcare Management Forum 21(3): 6-12.

Flood, C.M. and T. Sullivan. 2004. "Supreme Disagreement: The Supreme Court Affirms an Empty Right." Canadian Medical Association Journal 173: 142-3.

Simunovic, M., M.E. Theriault, L. Paszat, A. Coates, T. Whelan, E. Holowaty and M. Levine. 2005. "Using Administrative Databases to Measure Waiting Times for Patients Undergoing Major Cancer Surgery in Ontario, 1993-2000." Canadian Journal of Surgery 48(2): 137-43.

Sullivan, T., W. Evans, H. Angus and A. Hudson. (Eds). 2003. Strengthening the Quality of Cancer Services in Ontario. Ottawa: Canadian Healthcare Association Press.

Sullivan, T., M.J. Dobrow, A. Hudson and L. Thompson. 2004. "Reconstructing Cancer Services in Ontario." HealthcarePapers 5(1): 69-80.

Sullivan T. 2006. "Waiting for Cancer Care: Exploiting our National Laboratory." (Guest Editorial) Canadian Journal of Surgery 49(1): $12-4$.

\section{About the Author}

Terrence Sullivan, PhD is President and Chief Executive Officer of Cancer Care Ontario. He holds faculty appointments in the Departments of Health Policy, Management and Evaluation and the Dala Lana School of Public Health at the University of Toronto and is also Vice Chair of the Ontario Agency for Health Protection and Promotion and Chair of the Performance Committee of the Canadian Partnership Against Cancer. 